\title{
Effect of Music on Vital Parameters, Rate of Perceived Exertion and Six Minute Walk Distance in Normal Healthy Individuals
}

\author{
Vaishnavi Vivek Chiddarwar, Nilima Shirish Bedekar, Parag Kantilal Sancheti\&Ashok K \\ Shyam
}

\begin{abstract}
Aim: To find theeffect of music on vital parameters, Rate of Perceived Exertion and six-minute walk distance in normal healthy individuals. Method: The study was performed on 60 normal healthy individuals (18-25 years). 30 individuals performed six minute walk test with music on the first day and without music on the second day while, 30 individuals performed without music on the first day and with music on the second day. The vital parameters, Rate of Perceived Exertion were recorded pre and post the test (with and without music), six-minute walk distance was recorded. Results: On statistical analysis with unpaired t-test for parametric data and Mann Whitney $\mathrm{U}$ test for non-parametric data, there was no significant effect on the blood pressure ( $\mathrm{p}=0.91$ systolic blood pressure, $\mathrm{p}=0.93$ diastolic blood pressure), heart rate $(\mathrm{p}=0.87), \mathrm{RPE}$ $(\mathrm{p}=0.85)$, respiratory rate $(\mathrm{p}=0.43)$ or the six minute walk distance $(\mathrm{p}=0.12)$.Conclusion: Music had no significant effect on the walking performance of the studied population.
\end{abstract}

\author{
Vaishnavi Vivek Chiddarwar \\ B.Pth Intern, \\ Sancheti Institute College of Physiotherapy \\ E-mail: vaishnavichiddarwar@yahoo.com \\ Nilima Shirish Bedekar \\ Professor \\ Sancheti Institute College of Physiotherapy \\ E-mail: nilimabedekar@yahoo.com \\ Parag Kantilal Sancheti \\ Chairman \\ Sancheti Institute College of Physiotherapy \\ Ashok K Shyam \\ Orthopedic surgeon \\ Research officer \\ Sancheti Institute for Orthopedics and Rehabilitation \\ E-mail: doc.ashokshyam@gmail.com
}

Key Words: Music, Heart Rate, Blood Pressure, Walking, RPE

DOI: 10.18376/jesp/2018/v14/i1/111295

\section{Introduction}

Exercise is important in fitness, health promotion and in recovering from long standing health issues. It is a vital part to have a healthy life. Doing exercise should be a part of the routine and must be done regularly as the effects are not permanentlylasting. Physical inactivity has become an epidemic and also has been considered as, "The biggest public health problem of the $21^{\text {st }}$ century."(Stork et al,2015). There is hence, a dire need to incorporate physical activity in people's livesso, it should be made interesting to have compliance for it. Music is one such form which can help improve performance while exercising. Self-selected playlists have shown to improve Sprint Interval Training performance. [Stork MJ et al,2015]. Music has an effect on the mood, arousal and enjoyment when varied in tempo and mode [Thompson WF et al,2001]. Sixminute walk test (6MWT) is a sub-maximal exercise test that measures the functional capacity, it 
is easy to administer, better tolerated and more reflective of activities of daily living than the other walk tests. The $6 \mathrm{MWT}$ is a practical simple test that requires a $100 \mathrm{ft}$ hallway but no exercise equipment or advanced training for the examiner. [Enright P. L,2003]. Exercise is needed for fitness and health. Walking is one such type of exercise which can be easily performed without needing any equipment. Also exercises need compliance and regularity hence, it should be made recreational. If music is coupled with exercise, performance can be enhanced [Lee.S et al,2014]. There is a need to objectively measure the effect of music on vital parameters, six-minute walk distance(6MWD) and Rate of Perceived Exertion (RPE). The aim of this study was to find out the effect of music on vital parameters, six-minute walk distance and Rate of Perceived Exertion (RPE) in normal healthy individuals.

\section{Materials and Methods}

Study design: Experimental, within subject and counterbalancing (subjects become their own control to avoid matching/personal variation for two different groups). [Hicks, C.M,2009]

Sample Size: 60

Sampling Technique: Voluntary participation of the subjects. Inclusion Criteria:Normal healthy individual's age rangedfrom 18-25 years. Exclusion Criteria: Individuals having any musculoskeletal, neurological, respiratory or cardiac pathologies or acute condition which can hamper 6MWT.

Approval of the ethical committee was taken. Notice regarding the participation in the study was displayed in the college. Written consent of the participants was taken and the procedure was explained to them. A total of 60 participants (50 females, 10 males) were a part of this study with an average age of 21.8 years (SD: 3.25 ) and with an average BMI of $22.62 \mathrm{~kg} / \mathrm{m}^{2}$ (SD: 1.49 ). 30 participants performed six minute walk test with music (a common two song playlist with average beats of 120 beats per minute was used for all the participants, the music was played using a smart phone and headphones) on the first day and without music on the second day, 30 participants performed the six minute walk test without music on the first day and with music on the second day in an uninterrupted, well lit, well ventilated 10 meter long walkway which had the necessary markings made on the floor indicating the start and the end points. All the vital parameters (pulse rate, respiratory rate, blood pressure), RPE were measured pre and post the six minute walk test. The six minute walk distance was recorded post each test.

\section{Results}

On statistically analyzing the parametric data (six minute walk distance, respiratory rate, pulse rate, blood pressure) using the Unpaired T-test and the non-parametric data (Rate of Perceived Exertion) using the Mann Whitney $U$ test with the p value set at 0.05 , the results are as follows:

Table 1: Demographic data

\begin{tabular}{ll}
\hline Characteristics & $\begin{array}{l}\text { Mean(Standard } \\
\text { deviation) or } \%(\mathbf{n})\end{array}$ \\
\hline Age (in years) & $21.8(3.2)$ \\
BMI $\left(\mathrm{kg} / \mathrm{m}^{2}\right)$ & $22.6(1.5)$ \\
Females & $83.3 \%(50)$ \\
Males & $16.7 \%(10)$ \\
&
\end{tabular}


Journal of Exercise Science \& Physiotherapy, Vol. 14, No. 1 (January to June), 2018 ISSN: 0973-2020 (Print) I I OR Impact Factor = 5.23 UGC Approved [no.7485] ISSN: 2454-6089 (Online)

Table-2:Baseline parameters two groups

\begin{tabular}{|l|l|l|r|}
\hline Characteristics & $\begin{array}{c}\text { Without } \\
\text { music (Mean+SD) }\end{array}$ & $\begin{array}{r}\text { with music } \\
\text { (Mean+SD) }\end{array}$ & p value \\
\hline Systolic BP & $117.06(5.98)$ & $116.93(6.25)$ & 0.72 \\
\hline Diastolic BP & $78(5.09)$ & $77.67(4.46)$ & 0.8 \\
\hline Heart Rate & $77.53(9.47)$ & $77.76(8.59)$ & 0.91 \\
\hline $\begin{array}{l}\text { Respiratory } \\
\text { Rate }\end{array}$ & $17.23(3.56)$ & $17.17(2.84)$ & 0.8 \\
\hline $\begin{array}{l}\text { Rate } \\
\text { Perceived } \\
\text { Exertion (RPE) }\end{array}$ & $0.1(0.27)$ & $0.15(0.30)$ & 0.56 \\
\hline
\end{tabular}

Table-3:Between groups post walking parameters

\begin{tabular}{|l|l|l|l|}
\hline Characteristics & $\begin{array}{l}\text { Mean(Standard } \\
\text { deviation) } \\
\text { without music }\end{array}$ & $\begin{array}{l}\text { Mean(Standard } \\
\text { deviation) with } \\
\text { music }\end{array}$ & p-value \\
\hline Systolic BP & $122.33(6.41)$ & $123.46(7.33)$ & 0.91 \\
\hline Diastolic BP & $78.46(5.08)$ & $79.13(4.63)$ & 0.93 \\
\hline Heart Rate & $91.53(12.03)$ & $91.80(10.05)$ & 0.87 \\
\hline Respiratory Rate & $27.26(5.26)$ & $26.67(3.69)$ & 0.43 \\
\hline $\begin{array}{l}\text { Rate of } \\
\text { Perceived Exert }\end{array}$ & $1.31(1.06)$ & $1.53(1.10)$ & 0.85 \\
\hline $\begin{array}{l}\text { Walk Distance } \\
\text { meters }\end{array}$ & $517.10(60.99)$ & $542.44(68.42)$ & 0.12 \\
\hline
\end{tabular}

As seen in the tables (3) the six-minute walk distance (6MWD) covered is higher with music as compared to the distance covered without music. However, the difference is statistically insignificant with $\mathrm{p}=0.12$.

\section{Discussion}

It is a common practice to couple music with exercise. A study was performed to find out the effect of different types of music on maximal self-paced running performance, which showed that the participants performed better with less perceived exertion and higher peak heart rate when they were made to listen to fast music [Lee.S et al, 2014] Thakur AM, Yardi SS et al studied the effect of music on exercise performance. 30 healthy female college students aging between 18-25 years were made to walk on treadmill 3 times in a week without music oncewith slow music the next time and with fast music the third time.Duration and rate of perceived exertion were measured at the end of 
each session. Longer duration of exercise noted in groups who listened to any form of music-slow or fast as compared to individuals who didn't listen to any music while exercising. This could be due to many factors including dissociation, arousal, motivation etc. Also, same level of perceived exertion was recorded but, after a longer duration with music as compared to without music. [Thakur AM et al, 2015]. Karageorghis CI, Priest DL in the year 2012 completed a two-part study to study the effect of music on exercise which aimed at finding the potential mechanisms underlying the effects of music. The studies showed that during repetitive endurance type activitiesself-selected, motivational audio playlists enhanced affect, reduced rate of perceived exertion and improved energy efficiency and work output.There is evidence to suggest that carefully selected music can promote psychological benefits during high intensity exercise. The music is most effective when coupled with self-paced exercise in externally valid conditions. [Karageorghis CI et al,2012]. This is contrary to the findings of the present study as no significant effect on vital parameters and RPE were recorded. As the study was performed on normal healthy individuals and as six-minute walk test is a sub-maximal exercise test, there was no significant effect recorded on the vital parameters and RPE. The average six-minute walk distance covered was 538.24 meters with music while, the average six-minute walk distance covered without music was 520.57 meters (table 8,9) which indicates that the participants covered more laps and hence covered longer distance with music as compared to without music owing to the fast beats of the music which enhanced their walking performance. However, the difference was not statistically significant with $\mathrm{p}=0.12$. The limitation of the study is that it is performed on a small sample. The present study can be repeated with a larger sample size for obtaining significant results, there is a need to find out the optimal tempo of music that would further enhance the six-minute walk performance without distracting the individual.

Conclusion: In the present study, music with lyrics and average beats of 120/minute shows no statistically significant effect on the vital parameters, RPE and six-minute walk distance of the studied population.

\section{Acknowledgements:}

The authors are thankful to the principal of Sancheti Institute College of Physiotherapy- Dr. Mrs. Savita Rairikar for allowing them to conduct the study in the college premises and also the participants for co-operating and being a part of the study without whom it would not have been possible to successfully complete the study.

\section{References}

Enright, P.L.,2003. The six minute walk test. Respiratory care, 48(8), pp 783-785.

Hicks, C.M., 2004. Research methods for clinical therapists. Elsevier Health Sciences pp-98.

Karageorghis, C.I. and Priest, D.L., 2012. Music in the exercise domain: a review and synthesis (Part II). International review of sport and exercise psychology, 5(1), pp.67-84.

Karageorghis, C.I., Terry, P.C., Lane, A.M., Bishop, D.T. and Priest, D.L., 2012. The BASES Expert Statement on use of music in exercise. Journal of sports sciences, 30(9), pp.953-956.

Lee, S. and Kimmerly, D., 2014. Influence of music on maximal self-paced running performance and passive post-exercise recovery rate. The Journal of sports medicine and physical fitness. 56(1-2): pp (39-48)

Stork, M.J., Kwan, M., Gibala, M.J. and Martin Ginis, K.A., 2015. Music enhances performance and perceived enjoyment of sprint interval exercise. Med. Sci. Sports Exerc, 47, pp.1052-1060.

Thompson WF, Schellenberg EG, Husain G. Arousal, mood, and the Mozart effect. Psychological science. 2001 May;12(3):248-51.

\section{Conflict of Interest: None declared}

